\title{
EARNED VALUE MANAGEMENT IN AGILE PROJECTS
}

\author{
Filip Popović ${ }^{1}$ \\ Tatjana Atanasijević ${ }^{2}$ \\ Srdjan Atanasijević ${ }^{3}$
}

DOI: https://doi.org/10.31410/LIMEN.S.P.2019.17

\begin{abstract}
Earned value management, as project management practice for monitoring, reporting, forecasting, and controlling, is generally characteristic of traditional project management. The method reckons on baselined plans with fixed and well-defined scope. This technique measures cost and schedule upon a project baseline. A resulting simple set of metrics provides early warnings of performance issues and allows timely and appropriate adjustments. On the other hand, the Agile approach in project management focuses on maximizing Return of Investment through early and continuous delivery of value, as outlined in the Agile manifesto. What is not defined is in which way to manage and track the cost to evaluate actual ROI. A possible solution is to implement a well-known EVM in Agile by using only three basic planning parameters: Velocity, Estimated Backlog, and Cost.
\end{abstract}

Based on our results, EVM could be used effectively at sprint and release levels, to provide additional transparency of project progress to the stakeholders and to allow us to implement corrective measures just in time.

Keywords: Agile, EVM, ROI, Control, Forecasting, Sprint, Release.

\section{INTRODUCTION}

$\mathrm{I}^{\mathrm{n}=\mathrm{n}}$ n the last couple of decades, agile like approaches become the most utilized project management methodology, not only in the field of software development but also in the event of different types of products and services.

Agile project management, in comparison with traditional waterfall-like approaches, emphasis incremental delivery, and planning on the multiple levels, instead of thoroughly planning the whole project flow in the very beginning.

The agile approach moves things that we typically do in later stages earlier. This approach, known as the shift-left paradigm, converges on delivering value to the end customer, focusing on maximizing the return of investment through early and continuous delivery of value.

The Agile project management approach is implemented through a process of defining the product backlog into smaller and smaller subsets of work. That is structured in a top-down manner. At the lowest level of the product backlog, the work elements or requirements can be prioritized and assigned to teams. The self-organizing teams pull work from the project backlog and work the tasks to completion in a series of short, time-fixed Sprints or iterations. Sprints are often from 2 to 4 weeks long (EVM vs. Agile Project Management, 2016).

\footnotetext{
$1 \quad$ Comtrade Group, Comtrade Digital Services, Dublin, Ireland

2 Comtrade Group, Comtrade Digital Services, Dublin, Ireland

3 Comtrade Group, Comtrade Digital Services, Dublin, Ireland
} 


\subsection{Challenge - how to monitor earned value in Agile project}

The real challenge in software projects managed in an agile way is how to track and control the execution of the project. How to monitor the project status and, depending on the condition, perform specific corrective measures.

Moreover, the agile methodology doesn't define how to follow up and track the costs to evaluate ROI information. Usual metrics in iterations, such as burn-down and burn-up charts, don't provide these kinds of data.

A possible solution is the implementation of earned value management using only three basic planning parameters: velocity, estimated backlog, and cost. Earned Value Analysis (EVA) is a method that allows the project manager to measure the amount of work performed on a project beyond the basic review of cost and scheduled reports (Ghosh, 2015).

Moreover, the agile methodology doesn't define how to follow up and track the costs to evaluate ROI information. Usual metrics in iterations, such as burn-down and burn-up charts, don't provide these kinds of data.

A possible solution is the implementation of earned value management using only three basic planning parameters: velocity, estimated backlog, and cost. Earned Value Analysis (EVA) is a method that allows the project manager to measure the amount of work performed on a project beyond the basic review of cost and scheduled reports (Ghosh, 2015). In other words, Earned Value Method (EVM) is a method that measures actual performance against the original plan. It helps us to identify areas where the project performance is different than the plan.

EVM would identify schedule (SV) and costs variances (CV) as well as trends (SPI and CPI).

Critical parameters used as part of the EVM are presented in Table 1.

Table 1. Vocabulary of the EVM

\begin{tabular}{|l|l|l|}
\hline Abbreviation & Name & Description \\
\hline BAC & Budgeted at Completion & The original planned cost of the project \\
\hline EV & Earned Value & The value of the project's throughput. \\
\hline AC & Actual Cost & The amount of money spent during a time \\
\hline PV & Planned Value & The planned value of the project's throughput. \\
\hline SV & Cost Variance & $\begin{array}{l}\text { The difference between the value of the throughput and the } \\
\text { cost to produce it. }\end{array}$ \\
\hline CPI & Schedule Variance & $\begin{array}{l}\text { The difference between the value of the project's throughput } \\
\text { and the planned value of the project's performance. }\end{array}$ \\
\hline SPI & Cost Performance Index & $\begin{array}{l}\text { An efficiency indicator for measuring the value of the } \\
\text { project's throughput produced by each unit of the actual cost. }\end{array}$ \\
\hline EAC & Schedule Performance Index & $\begin{array}{l}\text { An efficiency indicator for measuring the rate at which the } \\
\text { project's throughput is meeting initial schedule expectations. }\end{array}$ \\
\hline ETC & Estimate at Completion & Projection of the total project cost at completion. \\
\hline VAC & Estimate to Completion & $\begin{array}{l}\text { Projection of the remaining funds required to complete the } \\
\text { project. }\end{array}$ \\
\hline
\end{tabular}


Successful utilization of EVM is dependent on the early determination of project baselines (such that BAC and PV are easily identified) as well as on the ability of the organization to record and retrieve actual progress made against the project and being able to report on actual costs incurred to make this progress happen (Ghosh, 2015).

\section{METHODOLOGY}

In this article, we have analyzed the possible implementation of EVM on the fixed priced project with fixed scope (Kamphorst et all, 2018; Rai \& Mehta, 2014; Atanasijević, 2016).

- To establish the initial baseline, we have used the following data points:

- The number of planned iterations;

- The total number of story points;

- Planned budget.

In the following sections, we will apply the approved EVM approach to a set of data from real projects to confirm the starting hypothesis (Atanasijević et all, 2019; Atanasijević et all, 2010; Dragićević et all, 2013; Atanasijević, 2019).

\section{RESULTS}

Our planned budget is equivalent to Budget at Completion parameter $(\mathrm{BAC}=82,000 €)$ which will be used in further calculations.

Based on these inputs, we could create the graph shown on Figure 1.

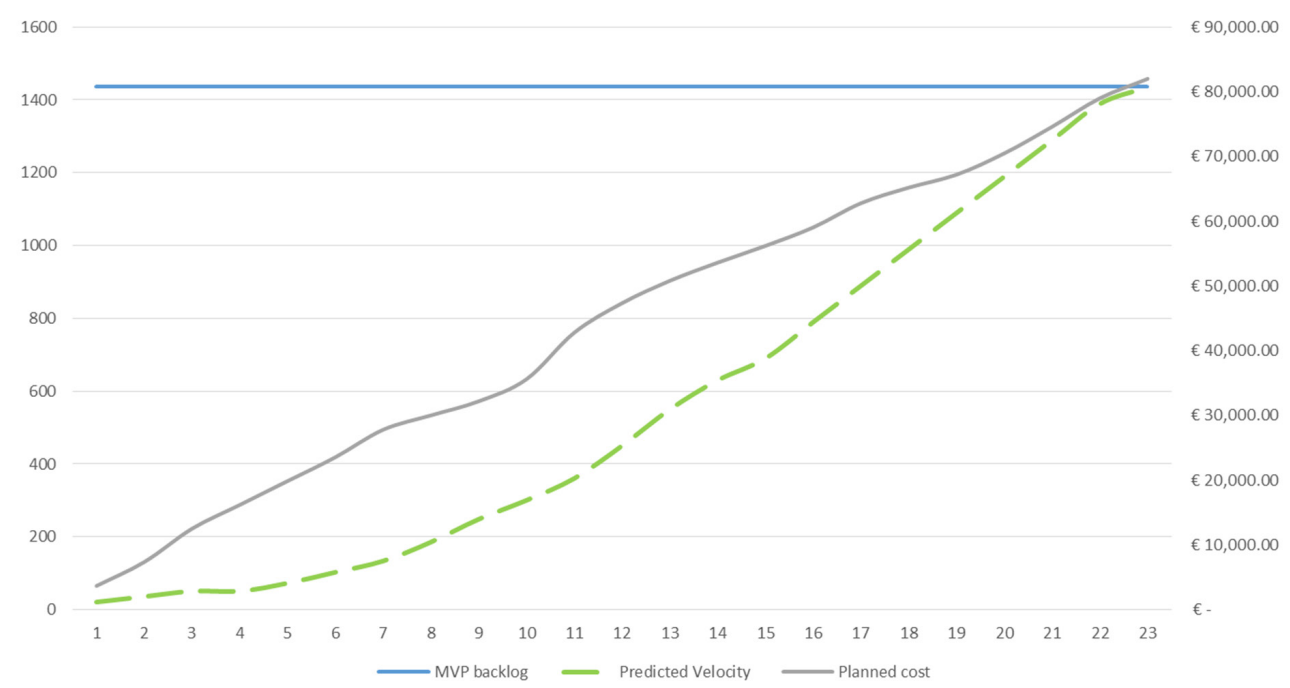

Figure 1. Scope, cost, and schedule projection

In the graph are presented baselines for costs and scope.

For further calculation of EVM parameters, we were looking for the following measurements:

- The number of story points completed;

- How many iterations we have achieved;

- Actual cost. 
After adding these metrics, we could get a better insight into project performance comparing with the original plan. What could be seen from the graph is that after 13 iterations, we are facing an inevitable delay in delivery and that we are spending more than initially planned?

To quantify schedule and cost variance first, we need to determine earned value. The two parameters without which EVM calculations cannot proceed are the Actual Cost for the Iteration (AC) and the actual number of points complete. In our case $\mathrm{AC}=€ 31,406$ and the number story points completed is 405 .

Earned value presents how much work was actually completed during a given period of time. It's derived by measuring actual work completed at a point in the schedule.

Since we have delivered 405 SP of 1436 SP it means that we have delivered $28 \%$ of the planned scope by the end of iteration 13 . That means that our earned value is equal to $28 \%$ of the predicted budget $(23,127 €)$.

Schedule variance is the difference between earned value and planned value:

$$
\mathrm{SV}=\mathrm{EV}-\mathrm{PV}=23,127 €-31,406 €=-8279 €
$$

In the same way, we could determine our cost variance. Cost variance presents the difference between what was expected to be spent and what is actually spent. Cost variance is then calculated:

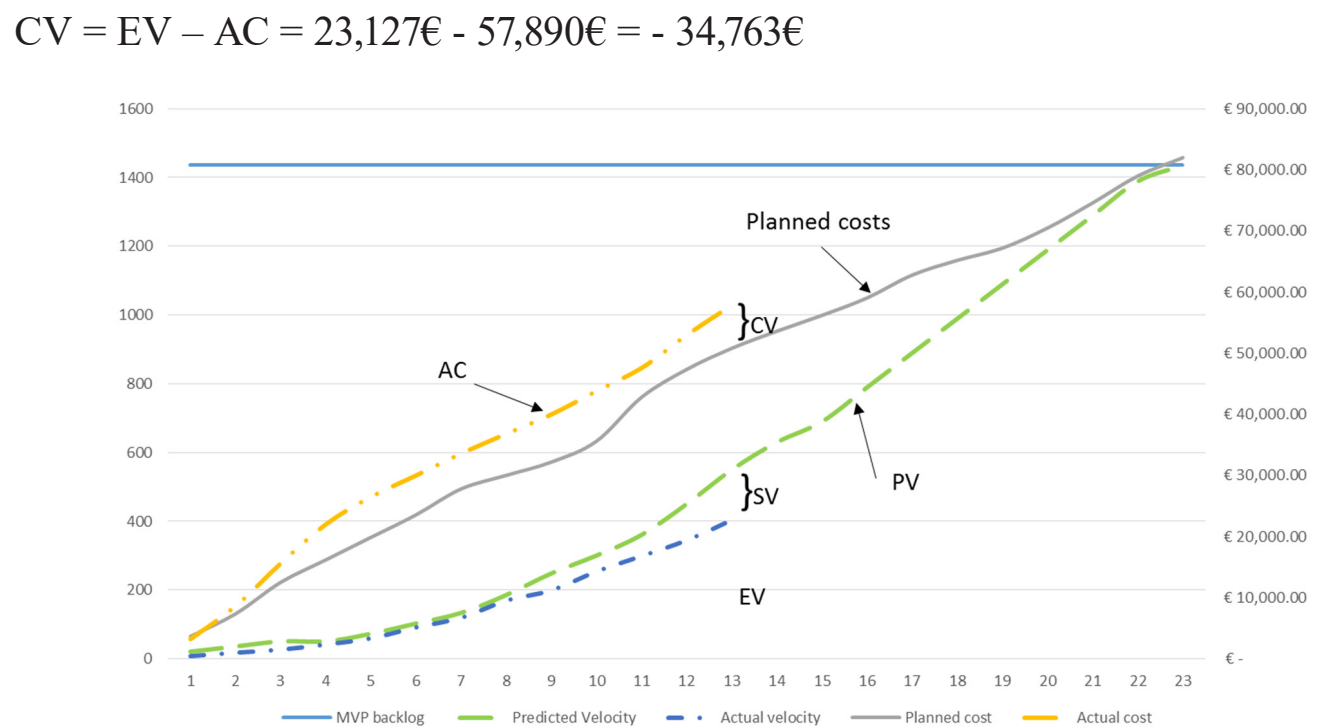

Figure 2. Scope, cost, schedule projection and performance

After determining schedule and cost variance we wanted to see what efficiency indicators, such as cost and schedule performance indicators, would indicate to us.

Cost performance index (CPI) shows how efficiently we are spending our budget compared to how efficiently we planned to spend them. It is calculated by dividing the Earned Value by the Actual Cost. In our project CPI would be:

$$
\mathrm{CPI}=\mathrm{EV} / \mathrm{AC}=23,127 € / 57,890 €=0.4
$$


Table 2. Decision table based on CPI index value

\begin{tabular}{|c|c|c|}
\hline $\mathrm{CPI}<1$ & $\mathrm{CPI}=1$ & $\mathrm{CPI}>1$ \\
\hline Over budget & On the budget & Under budget \\
\hline $\mathrm{EV}<\mathrm{AC}$ & $\mathrm{EV}=\mathrm{AC}$ & $\mathrm{EV}>\mathrm{AC}$ \\
\hline
\end{tabular}

Based on Table 2, a CPI of 1 would indicate that we are spending our budget to accomplish work at the rate that we had originally planned to spend it. A CPI less than 1, such as in our case, means that we are over budget by spending our budget less efficiently than planned. The reason for this is that our Earned Value is less in comparison with the Actual Cost.

The Scheduled Performance Index (SPI) compares Earned Value with Planned Value and is calculated by dividing the Earned value with Planed value:

$$
\mathrm{SPI}=\mathrm{EV} / \mathrm{PV}=23,127 € / 31,406 €=0.73
$$

This means we were $27 \%$ behind the schedule.

The analysis of the SPI is comparable to the CPI analysis, Table 3.

Table 3. Decision table based on SPI index value

\begin{tabular}{|c|c|c|}
\hline SPI $<1$ & SPI $=1$ & SPI $>1$ \\
\hline Over budget & On the budget & Under budget \\
\hline EV $<$ PV & EV $=$ PV & EV $>$ PV \\
\hline
\end{tabular}

The Estimate at Complete present valuable input as a forecast of the total amount that we will need to spend to complete the planned work, based on the actual work progress and trends. EAC calculation is to divide the Total Budget by the Cost Performance Index:

$$
\mathrm{EAC}=\mathrm{BAC} / \mathrm{CPI}=€ 82,000 / 0.4=€ 205,000
$$

This means that our original budget will extend 2.5 times than originally planned if present trends continue.

In same manner we have calculated the total number of iterations at completion, by dividing total number of planned iterations with calculated SPI.

$$
\mathrm{E} \text { (total \# iterations) } \mathrm{AC}=23 / 0.73=32
$$

From the iteration/sprint perspective, the usual tracking tool for monitoring progress is the burndown chart. "A burndown chart is a graphical representation of work left to do versus time" [2]. It is a graphical display of how quickly the team is working through the estimated and planned work. On the vertical axis is shown the quantity of remaining work, while the time is placed horizontally on the chart.

Burndown charts can be applied to any project containing measurable progress over time.

The burndown chart is beneficial for several reasons:

- monitoring the project scope creep,

- keeping the team running on schedule,

- comparing the planned work against the team progression. 


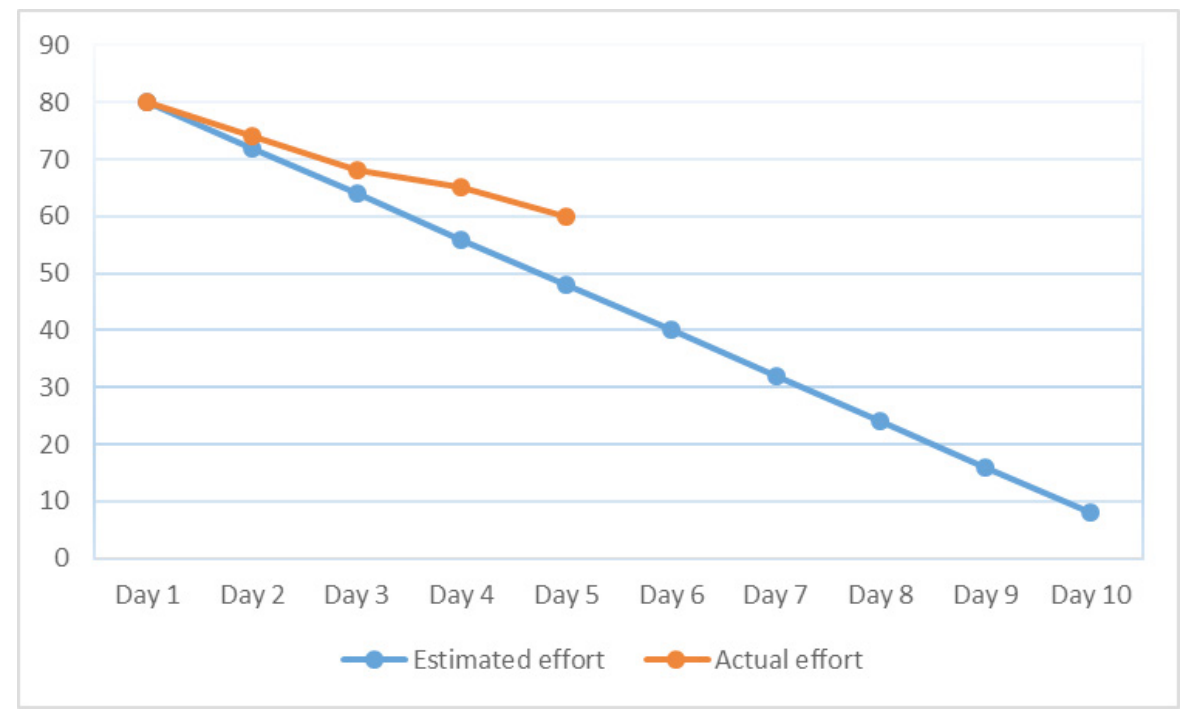

Figure 3. Burndown chart

\section{DISCUSSION}

As we look closely at Figure 3, we could see that the team is on halfway through the sprint and a slight delay in progress is occurring. If we consider that our EV is equal to 20SP and PV 32SP by simple calculation of schedule variance (SV) and performance index (SPI) we could actually quantify this delay.

$$
\begin{aligned}
& \mathrm{SV}=\mathrm{EV}-\mathrm{PV}=20 \mathrm{SP}-32 \mathrm{SP}=-12 \mathrm{SP} \\
& \mathrm{SPI}=\mathrm{EV} / \mathrm{PV}=20 / 32=0.62
\end{aligned}
$$

In the middle of sprint, we were $38 \%$ behind the schedule.

Analogue to the previous example we have calculated how many days in addition we would need to complete originally planned work if we have continued in same trend of progress.

Since our team worked in two-weeks sprints, which is equivalent to 10 working days, dividing with SPI:

$$
\mathrm{EAC}=10 / 0.62=16
$$

It is not a custom to perform cost analysis on the level of sprint but it is also possible

Our planned budget (BAC) for this iteration was estimated on $3600 €$, based on the number of present team members and man-day costs. Since total number of story points for this sprint was 80 it appears that value of one-story point is equivalent to $45 €$. Based on that we can simply calculate our EV in monetary value.

$$
\mathrm{EV}=20 * 45 €=900
$$

With this parameter we can perform other EVM calculations: 


$$
\begin{aligned}
& \mathrm{CPI}=\mathrm{EV} / \mathrm{AC}=900 € / 1800 €=0.5 \\
& \mathrm{EAC}=\mathrm{BAC} / \mathrm{CPI}=3600 € / 0.5=7200 €
\end{aligned}
$$

In the previous discussion, the usefulness of Earned Value Management (EVM) concept for Cost and Schedule variances within fixed-price projects, suggests how to manage costs in preagreed Delivery Cycles and also guides Project Managers for certain actions to address this issue. The utility of a scenario and action-based approach will help improve project performance as demonstrated through a real-life case, where the project was rescued using this approach.

\section{CONCLUSION}

The above example represents a basic implementation of EVM. The results above demonstrate how this simple approach can deliver an effective measuring of project performance and progress in an objective manner within an Agile development environment.

Earned Value measurements are excellent indicators that can be communicated to all project stakeholders, including the development team, so they gain a better understanding and insight into the financial impact of their performance (Ghosh, 2015; Atanasijević et all, 2019; Atanasijević et all, 2010).

Also, a Project Manager who is responsible for the financial performance of the project utilizes EVM as part of his or her project management toolkit to take better pro-active actions to steer the project in the right direction (Dragićević et all, 2013; Atanasijević, 2019).

Using these simple performance metrics in conjunction with typical Agile metrics (the Iteration burn-down and release burn-up charts for example) provides objective analysis for sharing with teams, management and customers. EVM metrics indicate early warnings validating that release plans should be changed and provide a business the opportunity to make priority trade-off decisions as early as it can in the project lifecycle.

\section{REFERENCES}

Atanasijević, S. (2016). Approach to project management in dynamic reality - Differences between traditional and agile approaches. doi:10.13140/RG.2.2.10519.27047/1.

Atanasijević, S. (2019). Managing AI Projects. doi: 10.13140/RG.2.2.10771.02080/1.

Atanasijević, S., Atanasijević, T., \& Zahar, M. (2019). PMO Approach in choosing the optimal Project Governance Framework for contracted engagement model. doi:10.13140/ RG.2.2.15466.06080/1.

Atanasijević, S., Stefanović, M., Atanasijević, T., \& Nedić, V. (2010). Customer Satisfaction Survey Analysis-Ultimate Tool for Measuring Quality of Software Services Today. In $4^{\text {th }}$ International Conference for Quality Research (pp. 299-308). Kragujevac, Serbia.

Dragićević, D., Milosavljević, A., \& Atanasijević, S. (2013). Combination of traditional and agile project management methodologies on software project of health information system in Ministry of Defence of Republic of Serbia. In 16. International Conference of Quality Management. Belgrade: ICDQM.

EVM (Earned Value Management) vs. Agile Project Management. (2016). [Blog].

Retrieved from https://blog.humphreys-assoc.com/evm-earned-value-management-vs-agile-project-management/ 
Ghosh, S. (2015). Systemic Comparison of the Application of EVM in Traditional and Agile Software Project. PM World Journal, 4(8).

Kamphorst, J., Mendys-Kamphorst, E., \& Westbrock, B. (2018). Fixed Costs Matter. SSRN Electronic Journal. doi: 10.2139/ssrn.3292536

Rai, V., \& Mehta, S. (2014). Understanding the Dynamics of Fixed-price Programs: A Case Study Illustration and Generalization. In $1^{\text {st }}$ Asia Pacific System Dynamics Conference. Tokyo, Japan. doi: 10.13140/2.1.2717.5041. 